\title{
Legal Design of Smart Rules and Regimes: Regulating Innovation
}

Michiel A. Heldeweg

Getting legislation right is essential if we are to deliver the ambitious objectives for smart, sustainable and inclusive growth, set out by the Europe 2020 Strategy

European Commission (2010)

There are no easy routes to regulatory improvement. Robert Baldwin (2005)

\subsection{Introduction}

The concept of 'smart rules and regimes' aims to focus attention on legal instruments that foster technological innovation while providing safeguards against technological risks.

The leading question of this contribution is why smart rules and regimes are relevant to policies fostering innovation and how they may be the object of a legal design methodology. The main objective of this effort is to emphasize that there is more to fostering innovation than deregulation, and to elucidate possible avenues for further research into legal design of relevant rules and regimes.

Firstly, I will present a (Dutch-based) viewpoint on the 'innovationregulation' relationship (section 3.2). Next I aim to provide clarification (in section 3.3) on the concept of 'smart rules and regimes', especially in relation to technological innovation. Subsequently, some ideas are presented (in section 3.4) on a possible legal design methodology towards the making of 'smart rules and regimes'. Finally, I will draw some conclusions and make suggestions for further research (in section 3.5).

\subsection{The 'Dutch (innovation) paradox'}

In my inaugural lecture on smart rules and regimes (Heldeweg, 2010), OECD comments (OECD, 2006) on the 'Dutch Paradox' concerning innovation in the Netherlands underpinned the relevance of adequate regulation for enhancing technological innovation. The findings of the OECD may be summarised by the following quote:

'An excellent record in knowledge creation, but a mediocre record in innovation activity' - with 'innovation activity' being defined as, '.. successful development and application of new knowledge in a new product and/or process'.

\section{Innovation}

The OECD survey prompted a study by the Dutch Scientific Council for Government Policy (WRR)1 called Innovation Renewed (WRR, 2008). The leading question in this WRR report is how government policies may improve Dutch innovation-capacity (WRR, 2008: 20). Innovation is regarded as a concept embracing both a process and its results in terms of a new functionality or a new way of using an existing functionality, both in the private and the public sector. Thus it is a 'complex system', which is not only about creating new knowledge and new technologies, but also about changes in organisation, management and labour, towards faster recognition, diffusion and application of (new) knowledge (WRR, 2008: 18). Innovation is not only about exploration (esp. inventions) but also about exploitation (esp. valourisation of new knowledge and of new technologies). The latter, however, seems to be problematic, also due to a shortfall in 'entrepreneurship'.

Failure at and in innovation

This shortfall may be linked to various forms of market failure concerning innovation. Major causes of this are: reluctance to initiate innovation with positive external effects, uncertainty on returns on 
investment, insufficient or slow knowledge transfer, small profit margins ('lack of slack'), and insufficient cooperation between firms (WRR, 2008: $58,83)$.

Next to market failure, there is 'systemic failure' within the innovation process itself (WRR, 2008: 55). A successful exploitation of new technology requires institutional changes within markets, such as new production and distribution chains, (accompanying) technical standards and safety protocols. Existing institutions, however, may impede innovation, for instance when a new product fails to pass a safety test (for introduction into the market) because its test criteria are based in existing technology.

\section{Government opportunities}

Government may have the potential to rectify market and systemic innovation failure. Technological innovation is a public interest, especially in view of global competition, sustainable development and the improvement of public services, such as energy, transport, health care and infrastructures (WRR, 2008: 29, 58). Taken intrinsically, government will focus on securing innovation as such, through securing or improving the 'general rules of the innovation game'2 rather than on any particular technology or related public service. Taken extrinsically, government interventions are geared by the promise of a particular technology to either function as a 'breakthrough' or 'general purpose technology' (e.g. electricity, chemistry, electronics, computers and the Internet), 3 or as a means to improve the quality or efficiency of specific public interests (e.g. energy, public transport, health care). Extrinsic attention may lead government to act as a leading or launching costumer, or as an initiator, a partner in PublicPrivate-Partnerships (PPP), a principal in innovative public procurement, and as legislator.

\section{More failure}

With regard to fostering innovation, government should operate on the basis of the 'additionality-principle'. It should intervene only when and where necessary (i.e. when markets and social networks fail at innovation), and must retreat as soon as possible (WRR, 2008: 31-2). Furthermore, involvement of private parties or indeed privatisation may be an important tool in the formulation and execution of public interest innovation policy.

The additionality-principle 'responds' primarily to the dangers of 'government failure' relating to innovation. The main examples of this are: lack of scientific knowledge (causing vulnerability to either misjudgements or to 'regulatory capture'); fragmentation of government innovation policies (resulting from bureaucratic divisions and struggles); 4 over-specificity in its requirements on deliverables (in terms of timeliness, technical standards, the requirement of universal access linked to subsidies or procurement - especially when innovation is still immature); and finally, over-regulation, administrative burdens, and inadequate fiscal and socio-economic policies.

A smart approach?

Clearly (apart from over-regulation) 'dumb regulation' must be avoided; especially technology-dependent regulation (Van Klink and Prins, 2002: 37-8). Such may be the case in rules on market admittance of substances and products, in normalisation within production and distribution chains and networks, in subsidy systems or public procurement strategies, and in regulatory prohibitions which aim to safeguard (especially) the environment, public health and public safety.

Still, avoiding 'dumb regulation' does not cover the full spectrum of legal strategies that 'smart rules and regimes' may provide. A broader and more systematic perspective is necessary. With smart rules and regimes in mind, we may relate to Roger Brownsword's three types of channelling conduct ' $x$ ' (Brownsword, 2008: 19-21). He distinguishes negative channelling ('So that agents shall not do x'; presupposing 'a rule that prohibits $\mathrm{x}$ '), positive channelling ('So that agents shall do $\mathrm{x}$ '; presupposing 'a rule that requires $\mathrm{x}$ ') and neutral channelling ('So agents may 
or may not do $\mathrm{x}$ ' - as they prefer; requiring 'a rule that permits $\mathrm{x}$ '). We may substitute 'conduct $\mathrm{x}$ ' with any particular kind of technological innovation (as applying 'technology $x$ ') and similarly channel the regulatory take on this particular kind of innovation as follows:

Table 3.1 Regulatory channelling of innovation (cfrm. Brownsword)

\begin{tabular}{|c|l|l|}
\hline Type of channelling & $\begin{array}{l}\text { Description of } \\
\text { conduct }\end{array}$ & $\begin{array}{l}\text { Typical norm of } \\
\text { conduct }\end{array}$ \\
\hline Negative & $\begin{array}{l}\text { 'Shall not do } \\
\text { Innovation x' }\end{array}$ & Prohibition \\
\hline Neutral & $\begin{array}{l}\text { 'May (not) do } \\
\text { Innovation x' }\end{array}$ & Permission \\
\hline Positive & $\begin{array}{l}\text { 'Shall do } \\
\text { Innovation x' }\end{array}$ \\
\hline
\end{tabular}

Brownsword adds four comments to this threefold 'regulatory range'. Firstly, that a 'negative channelling' (i.e. prohibition) leaves open the decision on modes of enforcement (penal sanctions, tort or administrative redress). 5 Secondly, that 'neutral channelling' (i.e. conduct being permitted) leaves open whether this comes with 'reservations' ('permission with negative reservation') or with encouragement ('permission with facilitation'). Thirdly, that in the absence of a blanket prohibition or unvarnished permission, we are likely to find a regulatory mix of public and private law rules. Fourth and finally, that regulation will hold a 'default position', called regulatory tilt, which projects a normative guideline if regulatory ambiguities need to be resolved or when regulation is silent on a point. In these cases the default position will either indicate prohibition or permission - ambiguity is resolved and silence interpreted assuming the tilt to be either against permission or against prohibition.

Clearly, this approach presents different avenues in which smart rules and regimes may be employed, with a view on fostering technological innovation, and will be of interest to a legal design methodology.

This calls for a further analysis of these three options, set out below, in which conduct towards ' $x$ ' may be understood as conduct favourable to technological innovation (the norm-object), and ' $y$ ' depicts the agent(s) addressed (the norm-subject).

'Prohibitive'. In the prohibitive ('y shall not do x') perspective, the focus is on risk regulation: 'regulating technological risk' (Fisher, 2010: $6,7)$, that is, the regulatory safeguarding of public interests in a clean environment, public health and public safety, against (outside) threats prohibitions, but also 'permissions with negative reservations'. This focus, however, must come with a view on how, while curbing or channelling exploration and exploitation of technology, risk regulation can meanwhile accommodate technological innovation.

This approach we name: 'innovative risk regulation'. In fostering innovation, the choice and design of regulatory restrictions should reflect innovation-efficiency and innovation-effectiveness. Innovation-efficiency is about avoiding over-inclusiveness of norms: prohibiting more than is necessary to protect vulnerable interests.

Targetedness of the regulated conduct is necessary to avoid such overinclusiveness (i.e. inefficiency). Detailed regulation may be the answer, but often comes with technical specificities that make restrictions vulnerable to technological innovation the aforementioned problem of technologydependency. Innovation-effectiveness is about promoting more desirable innovations by placing restrictions on existing or emerging technologies. Such restrictions could operate as a push towards a technological shift to a new or improved technological functionality. A mere prohibition (of certain technologies) may (similar to a command - e.g. of emission targets) promote innovation, if industry has sufficient (financial) resources and time to make necessary alternative investments, and if a level (competitive) playing field is safeguarded. A '(smart) regulatory mix', for example, may add an encouraging pull (the proverbial 'carrot') to the compelling push (the proverbial 'stick') such as by combining restrictions with subsidies or tax exemptions for first movers. In effect this shifts the regulatory 
response from 'negative' towards 'neutral' channelling.

'Permissive'. In a permissive ('y may or may not do $x$ ') perspective, our focus lies with creating favourable regulatory conditions towards enhancing technological innovation as a matter of private choice. We name this: 'innovation-facilitating regulation'.

'Permission with positive facilitation' would clearly fall into this category, but also, for example, creating a zone in which private actors 'may' and 'can' indeed (legally) pursue certain innovations, more restricted elsewhere.

The baseline of facilitation is to ensure the presence of a legal infrastructure favourable to technology innovation; based on public interest considerations but geared to foster private interests, so that private actors may act upon expected private 'gains'. A robust and attractive system of property rights (including intellectual property), sound and versatile contract and competition law, as well as trustworthy regimes for recognition of specialised knowledge, skills and performance (e.g. diplomas and certification) are essential.

In addition and more conducive (as 'pull'), some specific legal arrangements, innovation enticing, could provide interesting steppingstones towards innovation, such as: tradable public rights (e.g. emission allowances), legal grants (e.g. subsidies, favourable loans and securities), (re)allocation of property rights (e.g. removing 'anti-commons' barriers Heller, 1998), and regulatory competition (Tiebout, 1956).

'Compelling'. In a compelling ('y shall do x') perspective, innovation is a public interest that warrants active persuasion, through regulation that obliges innovative conduct. We name this: 'innovation-compelling regulation'.

Following four types of regulation, 6 this compelling regulatory perspective presents itself in many different examples. Firstly, through direct regulation, where conduct follows 'command and control' and breaches are punishable under law, which features prohibitions and commands aimed at shifting from existing undesirable technologies to new and promising technologies. Secondly, through indirect regulation, where conduct follows efficiency considerations and is sanctioned by - comparative economic disadvantage, such as by taxation (or by tort law). 7 Thirdly, through self-regulation, where conduct follows social considerations and is sanctioned by criticism and ostracism. Examples of compelling self regulation generally require that self-regulation transforms into intermediary regulation, in which regulation results from cooperation, such as where government (or a third party) operates as initiator or matchmaker. Public and/or private initiatives towards certification of products, services, processes and organisations (as a prerequisite to a go-ahead), are important examples. Operating as a launching (or leading) customer will require proper schemes of innovative procurement or schemes towards publicprivate partnerships. Furthermore, 'quangos' (i.e. independent regulators) or social enterprises (e.g. housing corporations, health care providers and universities) may be the intermediaries that initiate innovative projects (on the basis of a regulatory framework provided by government). Fourthly, the use of inherent regulation, where conduct follows inbuilt or systemic constraints of functionalities, 8 sanctioned by absence or loss of (physical) functionality. These may present themselves - compellingly - through the need to apply (or keep up with changes in) state of the art technology to (optimally) make use of a functionality. A low-tech example is the "speed ramp', while a high-tech example is adherence to internet protocols in providing and using ICT-services.

\section{Balancing act}

Clearly, this regulatory range indicates the balancing act that is needed. Not only must technological innovation be fostered, but there is also the public interest of securing against technological risks. Ideally both interests must be acted upon jointly, indifferent to whether the initiative to act lies with fostering innovation or curbing risks. Thus, there is an abundance of reasons to look more closely at what can be done to design regulation that can cope with the challenges, which the aforementioned balancing act presents us with. Consequently, focusing on the possibilities of designing 'smart rules 
and regimes' seems a sensible next step.

\subsection{The concept of 'smart rules and regimes'}

Conceptualising 'smart rules and regimes' focuses attention on legal forms of regulation and the general normative context that underpins and constraints their validity and bindingness. First, the concepts of 'rules' and of 'regimes' must be defined, preferably in simple and yet robust terms.

Rules are defined as linguistic statements, projecting a mode of conduct or a power conferred, which is prescribed or attributed (bindingly)9 in instances as defined within the rule (or its underpinning rules). In general, rules consist of: a 'subject', that is, the person(s) prescriptively addressed - subject ' $y$ ' in: ' $y$ shall/may or can (not) do x'; an 'object', that is, the conduct prescribed - conduct ' $x$ ' in: ' $y$ shall/may or can (not) do $x$ '; an operative mode, that is, the prescriptive modality - prescribing 'shall/may' or 'can' in: 'y shall/may or can (not) do x'; a 'norm-condition' (' $z$ ' in: 'y shall/may or can (not) do x, if and when z') (Ruiter, 2010).

A regime is defined as a system of (such) rules, which in conjunction includes not only norms, but also the mechanisms of decision making and the network of involved actors. 10 A regime holds at least the minimum of objective legal norms necessary to underpin subjective legal relations, such as in a permit or a subsidy scheme, and in (general) contract and property law. Some regimes are abstract (i.e. of general applicability - e.g. contract and property law), and some concrete (i.e. related to a specific interest - e.g. an environmental permit system or indeed an environmental law code).

\section{Wicked problems, smart response}

I name rules and regimes smart, in as much as they are more successful in adequately addressing the need for legal regulation in complex circumstances of:

- $\quad$ high societal or technological dynamics, which present a desire for adaptable (or self-adaptive) (systems of) legal norms which dynamically enshrine new/improved knowledge (technological innovation) or new/changed opinions/values (social innovation - often following technological innovation);

- major contrasts or rather conflicts of interests, presenting (more) fundamental differences in (opinions following underlying) values, which present a desire for (systems of) legal norms, which may mediate tensions between these values, such as between public and private interests, or between opportunity and risk.

A combination of these two circumstances - high dynamics and major conflict - presents a 'wicked (regulatory) problem' (comp. Rittel and Webber, 1973), such as is manifest in debates on technological innovation and the likelihood, magnitude and distribution of their risks and benefits. Clearly, these problems pose a challenge to regulatory governance, 11 that is, to the design of smart rules and regimes, aimed at balancing both dynamics and conflicts.

\begin{tabular}{|c|c|c|c|c|c|}
\hline \multicolumn{6}{|c|}{ Table 3.2 Positioning Smart Rules \& Regimes } \\
\hline \multirow{2}{*}{\multicolumn{2}{|c|}{$\begin{array}{l}\text { Dynamics (effective and efficient) } \\
\rightarrow \\
\text { Conflict } \downarrow \text { (legitimate \&legal } \\
\text { validity) }\end{array}$}} & \multicolumn{2}{|c|}{ societal } & \multicolumn{2}{|c|}{ technological } \\
\hline & & - & + & + & - \\
\hline \multirow[t]{2}{*}{ Private $\Leftrightarrow$ Public } & - & $-1-$ & $-1+$ & $-1+$ & $-1-$ \\
\hline & + & $+/-$ & \multirow{2}{*}{\multicolumn{2}{|c|}{$\begin{array}{l}\text { Smart rules \& } \\
\text { regimes } \\
+/+\end{array}$}} & $+/-$ \\
\hline \multirow[t]{2}{*}{$\begin{array}{l}\text { Risk } \Leftrightarrow \\
\text { Opportunity }\end{array}$} & + & $+/-$ & & & $+/-$ \\
\hline & - & $-1-$ & $-/+$ & $-/+$ & $-/-$ \\
\hline
\end{tabular}

$A$ '+' or '-' points at presence or absence of a confict or of dynamics

As to definitions, the concept of smart rules and regimes is not coined to delineate sharply between, smartness and dumbness, but primarily to express the ambition to overcome wicked regulatory challenges.

Smart rules and regimes are clearly relevant in two exemplary cases. Firstly, when fostering services of societal interest, there is a need to 
balance public and private interests in these services, in the context of dynamic changes in (primarily) political opinion (and/or in commercial strategies), on how and which services need be rendered. Secondly, when fostering technological innovation of societal interest, especially balancing advantages and risks of innovation, in the context of a context of dynamic changes in (primarily) technology (and society). 12 Table 3.2 shows how smart rules and regimes may thus be positioned the references to legitimacy, legal validity, effectiveness and efficiency will be clarified below).

In this contribution the focus is on fostering technological innovation, with a view on (a) strong dynamics (i.e. a stress on robustness and on adaptability) and on (b) avoiding unacceptable risks. Clearly, this touches upon the challenge addressed by, among others, Somsen (Somsen, 2009: 21 - translated by MAH):

The continuous safeguarding of the topicality of a regulatory regime, measured by the current state of technology, is the greatest and seemingly most hopeless challenge of technology regulation. [...] Effective regulation presupposes a procedural and institutional facility which facilitates a simple and fast adaptability of the regulatory regime to new technological factuality.

In this contribution, smart rules and regimes are discussed in terms of their ability to provide such an 'institutional facility'.

\section{Variables and maxims}

The smartness of rules and regimes relates to balancing two variables: high dynamics and strong conflicts of interests. This reflects underlying legal governance dimensions and accompanying principles or maxims of regulatory effectiveness and efficiency (under dynamic pressure) and regulatory legitimacy and legal validity (under pressure of conflicting interests). Clearly, the challenge, as described by Somsen, illustrates this. If legal norms do not 'align' with the current state of technology, they stand to become either (obsolete, hence) ineffective (i.e. inadequate in protecting against risks) and/or (obstacles, hence) inefficient (i.e. unnecessarily hampering the deployment of new technologies). Making these norms more adaptive to technological change may, however, put stress upon their legitimacy (e.g. through involving private rule making) or their legal validity (e.g. through discretionary overstretch in executive use or court interpretation).

Consequently, the design of smart rules and regimes must rest upon guidelines, which do justice to these legal governance dimensions and accompanying principles of good legal governance. These principles reflect both the requirements of the rule of law (as legal norms adherence - safeguarding freedom and fairness between government and citizens and among citizens reciprocally) and of serving the public interest (as governance optimality - ensuring that public interests be served properly and balanced). The latter ('proper public service') should lead to the design of effective and efficient regulatory strategies; the former ('fairness through the rule of law') to the design of legitimate and legally valid rules and regimes.

In this day and age, the term 'regulatory governance' points at the (vertical, horizontal and perhaps diagonal) 13 diffusion of regulatory power, following the postulate of legal pluralism, instead of the classic liberal legal underpinning (Scott, 2010). Within this context the regulatory governance debate especially addresses: 'the tensions between effective and instrumental regulatory governance, on the one hand, and demands for accountability and respect for process and rights within constitutionalism on the other.' (Ibid.).

Four dimensions, four principles

In keeping with this perspective, I proposed (Heldeweg, 2010) that the smartness of rules and regimes comprises a cumulative judgment on the aforementioned four counts, which I will now clarify.

Legitimacy is about 'which particular regulatory interventions can legally be brought about by who?' Its focus is on the id quod dimension 
(as opposed to modus quo - in legal validity) of the regulatory power to (unilaterally) bind others. Governmental legal acts are a major example. In the public law appraisal of state and government powers, legitimacy is the prime issue, as it delineates the demarcation between state power and citizens freedom(s). The issue, however, stretches beyond the context of government hierarchy (featuring binding government transactions). Other relevant archetypical 'institutional environments' of regulatory activity, are markets (featuring competition-based transactions) and social networks (featuring collaborative transactions - public or private).14 Each environment brings its own underpinning of legitimacy, pointedly described in terms of 'voice' (democratic legitimation of government), 'exit' (demand shifting to another supplier) and 'loyalty' (reciprocal willingness to cooperate). 15 As serving public interests may be left to (or be strongly influenced by) private actors, alternative institutional environments with their particular demands on legitimacy will likewise be relevant to the smartness of rules and regimes that shape and operate within these environments and the alignment of structures of governance and accompanying transactions (Van Genugten, 2008; Scott, 2010).

Legitimacy should be understood primarily in legal terms, as the legal power or competence to bind others legally or de facto, especially unilaterally. Even for government this will stretch beyond the concept of legality; in general 'legal authority under the rule of law' seems more fitting.16 In the context of technological innovation 'legitimacy' is the dimension determining which agents can authoritatively decide on the introduction and use of new technologies - either by governments (by democratic mandate), by markets (by consumers preferences), by social networks (by consent) or by some hybrid mix of these (all of the aforementioned?), either in public or private law legal forms or concepts.

Legal validity is about 'how a particular regulatory intervention may/ shall or can legally be brought about?' It focuses on the modus quo dimension of regulation in terms of the availability (and proper use) of regulatory legal tools (e.g. legislation, contracts and permits), respect for higher (written or unwritten) legal norms, and applicability of legal controls (i.e. enforceability and legal protection).

The full merit of 'legal validity' is realised only if and when we not only consider lawfulness in terms of (likeliness of) passing the test of judicial review by a court of law,17 but also, as a matter of (publicly debatable) 'justice', as in congruency with leading legal concepts and principles, such as 'distributive justice' and 'openness' or transparency' (apart from possibilities for a judicial test).

In the context of technological innovation this is the dimension where, in particular, the distribution of risks and benefits of innovation will be tested.

Effectiveness is about 'what particular regulatory intervention can practically be brought about?' It focuses on whether a rule or regime can result in intended (changes of) conduct. Effectiveness is served when rules and regimes adequately fulfil their functional potential to bring about the kind of conduct and/or activities, which is or are deemed beneficial to the particular public interest. With regard to individual norms, the following elements are of (major) importance in ensuring that a rule/regime adequately depicts and prescribes the desired kind of (pattern of) behaviour:

1. choosing the proper 'norm operator' - projecting the normative mode in terms of shall/may (not) or can, fitting to the desired conduct or power;

2. choosing the proper 'norm object' - projecting the conduct or empowerment as a proxy that is most in keeping with the relevant public interest (certainly not under-inclusive and, if possible, conducive); 18,19

3. choosing the proper 'norm conditionality' - determining whether or not the norm is of a categorical or a hypothetical normative mode; 20 4. choosing the proper 'norm subject(s)' - that is, addressing the proper agents (individual or general). Not only should a purposive fit of norms to public interests be ensured, but (unintended and) undesirable 
side effects (to the intended or adjacent public interests) must be avoided.21

Furthermore, fostering effectiveness requires ensuring, on a regime or system level, 'external coherence' or systemic effectiveness; avoiding a clash with other norms resulting in a conflicting prescription of conduct (conflicting requirements); ensuring certainty (measurability of adherence) and credibility of enforcement (and legal protection). Relating specifically to technological innovation, dynamic appropriateness must be ensured, safeguarding both robustness through adaptability (of content, interpretation or application) thus avoiding under-inclusiveness. The latter is especially relevant to the effectiveness of rules and regimes in the context of technological innovation and, in a way, is similar to a smart bomb's capability to adjust to a moving target so as to hit a target at least as good as when the target were motionless.

Efficiency is about 'how a particular regulatory intervention can practically be brought about?' It is concerned, firstly, with whether regulating is a 'cost-effective' policy effort to create presumably effective rules or regimes (as policy output). Secondly, it addresses the 'cost-effectiveness' of the rule or regime (as resulting from the regulatory effort) as regards the impact on the regulated conduct (as policy outcomes).

The output efficiency hinges on the relative regulator's costs concerning creation and management of regulation (including informing, enforcing and protecting). The regulator should aim to choose (types of) rules and regimes which (by comparison) incur the least regulatory management costs to the regulator (e.g. general rules; empowerment of norm-addressees to enforce among themselves; building upon existing rules and regimes).

The outcome efficiency depends on the relative behaviour adjustment costs of the regulatees (i.e. norm-addressees); for example, administrative burden, (profit) losses - some temporary, some structural.

The regulator should choose those (types of) rules and regimes, which cause (by comparison) the least regulatory or administrative burden on regulatees, by avoiding unnecessary 'juridification', over-regulation, over-detailed regulation, (over)fragmentation of (property) rights and powers (i.e. 'anti-commons'), and facilitation of self-regulation. On the level of individual norms these aspects are 'captured' by avoiding overinclusiveness through a proper choice of 'norm object' (not unnecessarily restrictive), of 'norm conditionality' (if possible hypothetical), 'norm subject(s)' (no more norm-addressees than necessary) - all of which amount especially to targetedness or precision: in 'smart bomb' terms, avoiding 'collateral damage'.22 On the level of regimes especially 'external coherence' (avoidance of conflicting requirements; fostering complementarities and synergy), but also legal certainty and credibility of enforcement (and legal protection) need be ensured.

Efficiency is here expressed in terms of the least in either regulators' regulatory management costs or regulatees' behaviour adjustment costs - least in a comparison of alternative rules and regimes being equal either as purported norms (effectively expressing the desired conduct - the regulatory output), or as conduct invoked (effectively in conformity with the norms). Efficiency is regarded as a relative (or comparative) concept, and is about whether the choice of a specific rule or regime comes without unnecessary cost or by comparison with the lowest (necessary) costs. 'Smoothness' of management or of behaviour adjustment - 'regulatory ergonomics' - comes with minimising the burden inflicted upon regulators and/or regulatees, and maximises output- and outcome-efficiency. Note though, that lowering costs as a matter of efficiency may (be) extend(ed) to creating or even maximising private benefits in alignment with relevant public interests; the rules and regimes become more efficient (i.e. more easily manageable or adjustable to), but also (and otherwise relevant to both regulators and regulatees) (more) profitable, which supports effectiveness.23

From the standpoint of technology innovation 'dynamic appropriateness' needs to be ensured, safeguarding targetedness through adaptability, focused on substantively safeguarding and, where possible, 'freedom from regulation' or a 'permissive tilt', again avoiding over-inclusiveness. 
This is similar to how a smart traffic light's adjusts to the absence of crossing cars, so as to avoid unnecessary waiting when there is no risk of crashing into another car.

In the above, the term 'smoothness' was used to describe the efficiency maxim in terms of (producing manageable, but especially of) creating user-friendly norms (the users being regulatees or normaddressees). The term 'ergonomics' was coined as possibly more fitting, as it expresses the notion of choosing and designing rules and regimes which optimally align with (existing) 'natural' behaviour or governance modes (including relevant (types of) values, preferences, incentives and inter-/transaction patterns).24 Thus, regulatory ergonomics (or ergonomics of regulatory governance) not only call for a lowering of the regulatory burden, but also the efficient allocation of obligations and (correlative) property rights (or entitlements). This means that the regulatory burden should preferably not be a serious impediment upon desired conduct, but insofar as it is, it should preferably be a burden only upon norm-addressees for whom it is, by comparison, easiest to shift the burden onto others; that is, transfer onto others, preferably as a result of a voluntary transaction (Ruiter, 2008). Furthermore, regulatory ergonomics are also promoted by clarity and simplicity of (systems of) norms, and a responsive/participative style of regulation enhances opportunities for rules and regimes to match norm- addressees' ' particularities'.25

Again, the 'how' of the efficiency dimension is concerned with measuring costs or burdens, but especially with comparing alternatives. Clearly, greater efficiency may indirectly enhance the effectiveness of the rules and regimes involved, as well as benefit legitimacy (if only by being less burdensome) and legal validity (since inefficiency may be a sign of disproportionality). 26

In analysing effectiveness and efficiency we find that some issues are, sometimes 'symmetrically', relevant to both. The first examples of this are 'precision and targetedness', and 'over-regulation', which relate to either over- or under-inclusiveness, amounting to either not reaching goals, otherwise harming the featured public interest or harming other public interests, or being over restrictive, thus unnecessarily limiting freedom and creating an unnecessary regulatory burden on both regulators and norm-addressees.

Another example are the abovementioned regulatory ergonomics, which are relevant in terms of enhancing functionality, especially through enabling ('make effective' - such as through tradable public rights) and avoiding transaction costs ('keep efficient' - such as through avoiding fragmentation and non-alignment with behavioural and governance patterns).

A final example of dual relevancy is the issue of robustness, either geared to retaining effectiveness (i.e. adaptability) or efficiency (i.e. targetedness).

\section{Name of the game}

Interdependencies between legitimacy, legal validity, effectiveness and efficiency, place the ideal of smartness of rules and regimes on a range between satisficing and optimising. As satisficing requires meeting minimum criteria for each maxim, not allowing any trade-offs; optimising, although initially geared towards best performance on each count, does also allow for balancing between dimensions or maxims (with respect of minimum criteria). Such balancing will not only need to reflect the nature of a given public interest and the kind of dynamism and or conflict with other interests, but must also relate to the nature of the (existing or proposed) 'institutional environment', as described in the above, of which hierarchy (government), competition (markets) and collaboration (social networks) are the archetypical forms.27 In practice hybridity between these forms, as in the example of a commercial enterprise (also) being involved in issuing public law certifications for technologically complex industrial installations, is ubiquitous. Hence, the evaluation of the smartness of the rules and regimes 
involved will hinge on whether there is sufficient alignment between governance and regulation, in terms of all four indicators. Legitimacy, for example, may suffer considerably when a commercial enterprise is bestowed with public powers, which in effect (e.g. through certification) push out competition - so private interests drive out public interests, or hierarchical powers distort the workings of the market.

\subsection{The concept of a legal design methodology (towards 'smart rules and regimes')}

Assuming relevance of smart rules and regimes in the face of the fostering of technological innovation, we need to consider their legal design.

\section{A methodology of legal design?}

By analogy, examples from industry, fashion and furniture suggest that to create 'legal objects' on the basis of a design (based in a design methodology) makes good sense. According to Ruiter,28 successful examples of such designs 'designate the projection of a type of artefacts with a function determining their form' .29 Similarly we may possibly create legal artefacts, depicted in their design as a specific form-function relationship, capable of performing or fulfilling legal functions.30 Especially rights (transferred as if they are objects), obligations (imposed as if they are burdens) and powers (conferred as if they are tools) are likely candidates of such legal artefacts - as are property, servitude and inheritance (Ruiter, 2010a: 2). To arrive truly at a general conceptual framework as a basis for a methodology of legal design, which (general guidelines) could operate in different areas of law (as smart rules and regimes may 'operate' as regulatory mixtures across different areas), we should leave behind the legal dogmatics of specific areas of law, such as civil or administrative law. A promising, more abstract, approach is to use concepts of 'legal theory', more specifically the theory on 'legal institutions' (Ruiter, $1993 ; 2001)$, such as marriage, property rights, corporations and public authorities (Ruiter, 2010a: 3-4).

\section{An institutional approach}

Legal institutions depict a normative mode of human behaviour in the form of (1) a system of rules (2) projecting a state of affairs (3) that ought to be realised (4) by a social practice regulated by those rules and (5) expressive of a common belief that the state of affairs is (6) actually the case. Element 2 (projecting a state of affairs) readily leads to a classification of different legal institutions, projecting: (1) a legal quality; (2) a legal status; (3) a personal legal relation; (4) an objective legal relation; (5) a legal configuration - and furthermore, (6) (through 'personification') legal subjects and (7) (through 'reification') legal objects. These basic legal forms, delineated as possible legal design objects, may be geared towards providing design guidelines, derived from (1) the general features of all legal institutions and (2) the specific features of legal institutions of different classes (Ruiter, 2010a: 7-10 - also including examples of such guidelines). Clearly, such guidelines primarily relate to - by analogy - the 'drawing of the dress' (i.e. the design of a legal artefact), rather than the 'dress made' (i.e. a specific instance of such legal artefact). Legal design is, after all, primarily concerned with conceiving, as concepts, possible institutional practices and their corresponding 'systems of legal norms suited to elicit and control such practices' (Ruiter, 2010b: 4). As such the design of concepts of legal artefacts provides the foundation for (guidelinebased) conceptualisations of individual instances of such artefacts, suited to a particular situation.

\section{An internal perspective}

A methodology of legal (institutional) design should primarily consider the internal structure of 'legal institutions as systems of norms'. A major focus would be to determine how the 'constitutive elements' of such legal systems could properly be framed: the legal norms themselves (Ruiter, 2010c: 1). A fitting methodology could firstly address rules projecting legal norms of conduct and, secondly, rules projecting powerconferring norms legal acts.

As to the design of legal norms of conduct ('x shall/may (not) do 
y (when Z)'), Ruiter proposes that their design should adhere to the following three guidelines: 31

1. take into consideration the four basic components of every norm: Subject ('x'), Object ('y'), Operator ('shall or may (not)'), and Conditions (' $z$ ');32

2. decide to which extent the logical oppositions (in variations of 'shall or may (not) do': command, prohibition, permission and dispensation) are relevant determinants of the design;

3. establish whether the design is such as to generate legal relations (according to Hohfeld) of a 'claim-duty' or 'privilege-no-claim' nature (discriminating between different kinds of rights - 'claims' and 'privileges' - and their legal opposites - 'duties' and 'no-claims'), and, if so, whether the respective rights holder positions and rights addressee positions are properly specified (in terms of unital and multital relations - MAH).

These three guidelines summarise an analysis, which specifies normcomponents and presents categorisations of norms, types of rights, and rights holders and addressees.

Framing the norm-components strikes a chord with the above analyses of the dimensions of effectiveness and efficiency, especially in terms of defining 'inclusiveness' (and avoidance of over- and under-inclusiveness) which makes 'guideline 1.' especially relevant to smart rules and regimes. Combining the positions of the components object and operator, yields four basic types of norms of conduct ('command', 'prohibition', 'permission' and 'dispensation') together with their reciprocal relations: contradictory, contrary, subaltern or subcontrary. This basic understanding is indispensable, for instance, for the concept of a regulatory range (channelling conduct) and regulatory tilt, as well as for reasons of legal system-consistence (especially relating to effectiveness and efficiency, and indirectly to legitimacy and legal validity) - hence we also need to take 'guideline 2.' into consideration. This is particularly challenging as legal language brings with it the ability to express the 'shall-operator' in terms of the 'may-operator' and vice versa. Thus, a command (an 'ordered act') is the negation of dispensation (the 'allowance not to act'); prohibition (an 'order not to act') is the negation of permission (an 'allowance to act'); permission (supra) is the negation of prohibition (supra); and dispensation (supra) is the negation of command (supra). Careful consideration is clearly of vital importance and must come with reflection on systemic aims (such as regulatory tilt) and regime consistency.

Similarly, we may use Wesley N. Hohfeld's four fundamental types of legal rights ('claim', 'privilege', 'power', 'immunity'), within four types of legal relations, as two groups of two types of rights-relations, either as relations based in norms of conduct or as relations based in norms of competence (to change norms of conduct). As to norms of conduct a 'claim' has a 'duty' as its legal correlative and a 'privilege' has a 'no-claim' position as its correlative. The positions of rights holders and rights addressees may be 'unital' (one person of closed group) or 'multital' (an open class of persons), which leads to eight different types of (claim - duty and privilege - no-claim) legal relations. Clearly, considering earlier remarks on effectiveness and efficiency relation to norm-subjects, adherence to 'guideline 3.' is called for.

Next to norms of conduct we must consider power-conferring norms, or norms of competence, which enable one or more agents to create 33 or abolish legal norms (Ibid. 2000c:1). Such a 'norm of competence' requires that we introduce, in addition to the norm-operators 'shall' and 'may', a third norm-operator: 'can', signifying the ability to bring about legal effects especially through the performance of a legal act (e.g. legislation, contracting). Empowerment to perform such legal acts must come from within the legal order and is met, within that order, by the correlative 'liability' of others to adhere.

Similar to norms of conduct (claim and privilege), there is a square of rights and (two) legal relations following from norms of competence: power, vis-à-vis its correlative liability, and immunity, vis-à-vis its correlative no-power). Again, it is relevant to distinguish between (in all 
eight types of relations based on) unital and multital rights holder and rights addressee positions.

Reflection on (1) norm-components, (2) logical oppositions, and (3) types of legal relations is vital to the making of (regimes of) legal rules, and the specific nature of norms of competence should be well understood. The power to create or abolish legal norms is, of course, vital in order to ensure that norms are adaptable in the face of technological innovation - apart from other mechanisms, such as changing modes of interpretation of abstract terms and conditions. Different classes of competence norms may be categorised, underpinning different classes of legal acts (Ruiter, 2010d: 9-10). Design guidelines should accommodate the making of such different types of norms.

\subsection{Conclusions and the way forward}

The leading proposition to this contribution has been that smart rules and regimes provide a useful framework towards understanding the regulation-innovation relationship, as well as towards the legal design of such rules and regimes.

The ideas behind such design, especially as phrased by Ruiter, open the perspective of framing smart rules and regimes as legal institutions. Clearly, this translates quite readily into possible guidelines concerning the internal structure of legal institutions, especially norms of conduct, norms of competence and legal acts. Such guidelines may well prove indispensable to addressing the question of how some internal structures may be smarter than others in terms of the four dimensions (and corresponding maxims) as coined in the second paragraph.

In particular, matters of effectiveness and efficiency (dimensions) may be addressed on the design level of legal norms by components such as the determination of the norm-operator, norm-object, norm-subject and norm-condition. Apart from legal consistency, however, an institutional perspective on legitimacy and legal validity is less apparent. As much as effectiveness and efficiency are relevant to regulating technological innovation, so are legitimacy (as in who decides on setting certain standards for new technologies) and legal validity (as in safeguarding legal certainty as a precondition to investing in innovation). Consequently, in terms of legal design, we need a framework or methodology that also addresses these two dimensions and accompanying principles.

\section{Internal and external}

At this stage of analysis, we must acknowledge that the focus on the internal structure of legal institutions must be matched by a broader design scope, encompassing both rules and regimes. Legal institutions will often be framed as regimes, forming a conjunction of rules as a system, projecting the institution. The internal make-up of such regimes - how to frame a conjunction of rules - is a primordial challenge to the design of smart regimes.34 Subsequently, the focus on the internal structure needs to be matched by an external view on the legal consequences of regulatory governance or policy considerations. This seems especially relevant as regards legitimacy and legal validity.

The need for such an external perspective, however, is important to all dimensions and principles. The regulatory governance considerations and proposed strategies which go under the labels of 'Better Regulation' (OECD, 1995 and 2005; EC, 2002, 2005) and 'Smart Regulation' (Gunningham et al., 1997 and 1998; EC, 2010), seem proper 'illustrations' of the impetus, scope and focus of such strategies towards an improved regulatory contribution to (among others, sustainable) innovation and growth. Especially the references by Gunningham et al. to 'regulatory design processes', 'regulatory principles' and 'instrument combinations', hold a promise on these counts - even though their proposals seem more focused on framing the policy process than providing guidelines for legal design.

Design of regulatory channelling and tilt

On a more specific note, the institutional take on legal design and smart rules $\&$ regimes may already provide a relevant analytical tool to elaborate 
methodically on the concept presented in the first paragraph and based on Brownsword's notion of a 'regulatory range' or of 'regulatory channelling'. Applied to (especially fostering) technological innovation, we should, as a matter of legal design, be able to express such regulatory strategies (including reservations, facilitation and tilt) in terms of the squares of normative oppositions (command, prohibition, permission and dispensation), and the contrary, contradictory, subcontrary and subaltern relations between rules fitting to these strategies. Thus a methodologically more sophisticated perspective seems feasible on the possibilities of design rules and regimes that express regulatory strategies becoming technological innovations.

\section{Summing up}

So, our quest continues. It will address both the general scope for a legal design methodology and the specific angle of regulating innovation. As to the latter, focal points of a design methodology of smart rules and regimes should be, on the one hand, determining design guidelines with respect to adaptability and ergonomics of rules and regimes, and on the other hand, guidelines concerning mixing of legal instruments as the challenge of building optimal legal regimes, as regards technological innovation and in keeping with maxims of legitimacy, legal validity, effectiveness and efficiency.

\section{Notes}

1. Wetenschappelijke Raad voor het Regeringsbeleid. Available at http://www. wrr.nl/english/. Accessed on 25 September 2011.

2. Especially basic requirements (e.g. legal certainty and trust through a basic legal infrastructure) and avoidance of institutional barriers (e.g. technical standards).

3. Expected to trigger, as did the examples mentioned, many other innovations and thus contribute significantly to (economic) welfare.

4. This fragmentation links with the economic concept of anti-commons: a fragmented pattern of many holders of rights in (scarce) resources (i.e. government powers) each of which is potentially prohibitive for pushing ahead with an innovative project, thus causing underuse of the resource (Heller, 1998). 5. Brownsword (2008: 15) also refers to the work by Murray and Scott (2002) in which three dimensions of regulation are distinguished: goal/rule/norm; monitoring; behaviour modification (Murray and Scott, 2002: 500-5).

6 . We use the distinction in regulatory modes as presented by Murray and Scott (2002: 500-5) - following especially earlier work by Lessig.

7. Subsidies, loans, securities and tradable allowances, also fall within this group, but these - generally - belong to 'facilitative regulation', whereas here the focus lies on more compelling instruments, such as taxes. In practice, of course, all these instruments may be either more facilitative or more compelling, depending upon specific circumstances and individual preferences.

8. Also referred to as 'design built' or 'architectural' control or regulation (Murray and Scott, 2002), for example, artefacts, machines, products, services, production processes and infrastructures.

9. We take the view here that legal bindingness (based upon validity) is the default presumption, but does not exclude the possibility of mere moral bindingness.

10. This definition includes elements as presented by Levi-Faur (2010: 20).

11. This term will be explained in the below (see variables and maxims).

12. And of course these cases may be combined as often technological innovation leads to societal innovation.

13. 'Vertical' as in multi-level regulation; 'horizontal' as in multi-actor regulation; 'diagonal' as in problem-based cross-cutting horizontal and vertical (comp. Osofsky, 2009).

14. Within these 'institutional environments' different 'governance structures' define the state of play (i.e. organise transactions), such as contracts and firms on markets, cooperation within networks, administrative acts within hierarchy. Note that in institutional economics 'hierarchy' may refer to the governance structure of government but also to that of a firm (which is, internally, organised hierarchically) (See van Genugten, 2008).

15. Note that all three notions of legitimacy imply 'accountability', either democratically (as in the joint adages: 'no power without accountability' and 'no accountability without power'), in a meeting of supply and demand (through a barter involving an exchange of information), and in reciprocal activity (towards a shared/common objective).

16. Notions of political philosophy are clearly relevant (as is the concept of good legal governance), but only in as much captured within the legal framework (of the rule of law) - such as in 'democracy under the rule of law'.

17. The term 'likeliness' is used to depict that often, in practice, situations 
arise which do not allow for a ready or immediate judgment in terms of lawfulness - i.e. there is no consensus to that effect - and so a 'digital' legal qualification (i.e. lawful or unlawful) of a contested act or state of affairs is (for the time being) 'indeterminate' (and possibly subject to propositions and hypotheses, based upon doctrinal legal theory).

18. The importance of a good proxy may point at two different aspects: 1 . the best description of the desired kind of behaviour (given that regulation is necessarily abstract and porous/underdetermined) - for example, 'establishment' as a forbidden industrial activity unless permitted (matching norm (output) and possible factual conduct (as outcome)); 2. the best behavioural mode considering the relevant public interest (given that this interest may be served by different kinds of behaviour) - for example, provisions prescribing targets versus prescribing use of certain means in curbing pollution by industrial emissions (matching outcomes in conduct with outcome in fostering the public interest).

19. Conduciveness is fostered by positive incentives, such as conviction (i.e. 'the right thing to do') or greater efficiency (i.e. less costs or more gains/ profits for norm-addressees - e.g. tradable allowances) so as to align private behaviour to public interests.

20. Compare: ' $Y$ shall not do $\mathrm{X}$ ', as in ' $\mathrm{X}=$ killing or stealing' (categorical prohibition); ' $\mathrm{Y}$ shall not do $\mathrm{X}$ when $\mathrm{Z}$, as in ' $\mathrm{X}=$ drive a car without lights on' and ' $\mathrm{Z}=$ after sunset' (hypothetical prohibition).

21. For example (1) by prohibiting pollution of 'type $X$ ', producers shift to or increase their pollution of 'type $\mathrm{Y}$ ' - possibly even more detrimental to the environment as the relevant public interest. For example (2) negative side effects on an adjacent public interest: environmental norms which lead to practices that jeopardise safety in the workplace. Of course, trade-offs between different public interests are often unavoidable.

22. The 'smart bomb' metaphor describes a bomb smart enough to redirect itself. Mainly to be able to hit a moving target, but possibly also to ensure that no unnecessary ('collateral') harm is inflicted (i.e. to other objects/subjects than intended).

23. In turn this relates to the distinction between transaction costs and production costs (and effects), upon which this contribution shall not elaborate. Consider though, as an example, establishing or adjusting a chemical plant in accordance with new emission norms, to operate subsequently profitably also by selling redundant emission capacity.

24. The IEA (International Ergonomics Association) defines 'ergonomics' (or 'human factors') as 'the scientific discipline concerned with the understanding of interactions among humans and other elements of a system, and the profession that applies theory, principles, data and methods to design in order to optimise human well-being and overall system performance. (IAE website [retrieved 27 February 2011]: http://iea.cc/.) The work of ergonomists is, again according to the IEA, concerned with 'the analysis of human-system interaction and the design of the system in order to optimise human well-being and overall system performance'. The analogy, of course, is the 'fit' between norm-addressees and regulation, and the ambition of optimally balancing 'norm-addressees well-being' and 'overall regulatory system performance'. 25. This point is also addressed in the 'Better Regulation'/'Smart Regulation' debate - see the references in the conclusion of this chapter.

26. Compare Sharpf's analyses on 'output-legitimacy' (Scharpf, 1999).

27. See endnote 14 on these 'institutional environments'. Furthermore, we will not go into the nature of this game in terms of being a '(non) zero- sumgame'. 28. So far published only as pre-publications on the LEGS website (http://www. utwente.n1/mb/legs/), but to be published in the near future (for reference see LEGS website).

29. To also write 'type' in italics is my personal choice, as it refers to a generalised perspective on the function-form relationship and the possibility of multiple use of the design (in cases where the same boundaries apply). 30. And not otherwise, such as, mean and lean, 'copy-paste' strategies, with only minor amendments (on dates, names, objects ...). Thus existing legal artefacts are used as a design-form for other artefacts of a similar type. Merely applying a form(at) does not amount to design, especially if it lacks the reflection on methodological accurateness of this de facto design for the functionality of the specific object of creation.

31. Quoted almost literally (Ruiter, 2010c: 10).

32. The latter component is not relevant in categorical norms - at least not in terms of a legal constraint.

33. Creation implies the possibility of changing.

34. Consider, for example, how framing a conjunction of a (simultaneous) permission

('may do x') and an exemption ('may not do x'), which amounts

to 'freedom' ('to do or not to do x'), may be regarded as a norm (as a strong or positive permission/exemption) or as absence of a norm (no prohibition and no command - a weak or negative permission) (von Wright, 1963: 86; Ruiter, 2010c: 2). Of course, such conjunctions may also be applied in the 
design of legal rights, according to the Hohfeld squares of legal relations.

\section{References}

-Baldwin, R., 'Is better regulation smarter regulation?', Public Law, (2005), pp. 485-511.

-Brownsword, R. Rights, Regulation, and the Technological Revolution (Oxford: Oxford University Press, 2008).

- European Commission, Simplifying and improving the regulatory environment (Action Plan on Better Regulation), Com (2002) 278 final, Brussels, June 2002.

- European Commission, Better Regulation for Growth and Jobs in the European Union, COM (2005) 97, Brussels, March 2005.

- European Commission, Smart Regulation in the European Union, COM (2010) 543 final, Brussels, November 2010.

- Genugten, M. L. van, The Art of Alignment: Transaction Cost Economics and the Provision of Public Services at the Local level (Dissertation, University of Twente, 2008).

- Gunningham, N. and D. Sinclair, Designing Smart Regulation, OECD web publication, 1997. Available at http://www.oecd.org/dataoecd/18/39/33947759.pdf. Accessed on 25 September 2011.

- Gunningham, N., P. Graboski and D. Sinclair, Smart Regulation. Designing Environmental Policy (Oxford: Oxford University Press, 1998).

- Heldeweg, M. A., Smart Rules \& Regimes. Publiekrechtelijk(e) ontwerpen voor privatisering en technologische innovatie (Elaborated inaugural lecture, Enschede,

University of Twente 2010).

- Heller, M., 'The Tragedy of the Anticommons', Harvard Law Review, vol. 1 (1998).

- Klink, B. van, and C. Prins, Law and Regulation. Scenarios for the Information Age

(Informatization Developments and the Public Sector Nr. 7), (Amsterdam: IOS

Press, 2002).

- Levi-Faur, D., 'Regulation \& Regulatory Governance', Jerusalem Papers in

Regulation \& Governance, Working Paper No. 1, February 2010.

- Mandelkern Group on Better Regulation, Final Report (on Better Regulation),

13 November 2001. Available at http://ec.europa.eu/governance/better regulation/documents/mandelkern_report. pdf. Accessed on 25 September 2011.

- Murray, A. and C. Scott, 'Controlling the new media: hybrid responses to new forms of power', Modern Law Review, (2002), p. 491.

- OECD, From Red Tape to Smart Tape (Paris: OECD, 2003).

- OECD, OECD Guiding Principles for Regulatory Quality and Performance (OECD, 2005).

- OECD, Economic Surveys, Netherlands (Paris: OECD, 2006)

- Osofsky, H. M., 'Is climate change 'International'? Litigation's Diagonal Regulatory

Role', Virginia Journal of International Law, vol. 29 (2009) no. 3, pp. 585-650.

- Rittel, H. and M. Webber, 'Dilemmas in a general theory of planning', Policy

Sciences, vol. 4 (Amsterdam: Elsevier Scientific Publishing Company, Inc.,

1973). Reprinted in N. Cross (ed.), Developments in Design Methodology

(Chichester: John Wiley \& Sons, 1984).

- Ruiter, D. W. P., Institutional Legal Facts, Legal Powers and their Effects (Dordrecht:

Kluwer Academic Publishers, 1993).

- Ruiter, D. W. P., Legal Institutions (Dordrecht: Kluwer Academic Publishers, 2001).

- Ruiter, D. W. P., 'Four Legal Methodology Papers' (a. A Methodology of Legal

Design; b. A Methodology of Legal Institutional Design; c. A Methodology of Design of Legal Norms of Conduct; d. A Methodology of Design of Power Conferring Legal Norms; e. A Methodology of Legal Acts), working papers, University of Twente, 2010 (a-e). Forthcoming (at http://www.utwente.nl/mb/legs/).

- Ruiter, D. W. P., 'Calabresi and Melamed's entitlements: a Hohfeldian approach to 'The Cathedral', in M. L. van Genugten and M. Harmsen (eds), De vorm behouden, verslag van een levenswerk door Dick W. P. Ruiter (Enschede: University of Twente, 2008), pp. 61-87.

- Scharpf, F.W., Governing in Europe: Effective and Democratic? (Oxford: Oxford University Press, 1999).

- Scott, C., 'Regulatory governance and the challenge of constitutionalism', EUI

Working Papers (RSCAS 2010/07), Robert Schuman Centre for advanced studies, Private regulation Series-02, 2010.

- Somsen, H., 'Rechtvaardige en doelmatige regulering van medische biotechnologie: embryoselectie en biobanken', in H. Somsen, J. Bovenberg, and B. van Beers (eds), Humane biotechnologie en recht (Deventer: Preadviezen NJV, 2009). - Tiebout, C., 'A pure theory of local expenditure', Journal of Political Economy, vol. 64 (1956) no. 5, pp. 416-24.

- Wetenschappelijke Raad voor het Regeringsbeleid (WRR), Het borgen van het publiek belang. Rapporten aan de regering nr. 56, 2000 (ISBN 901209058x). - Wetenschappelijke Raad voor het Regeringsbeleid (WRR) Innovatie vernieuwd. Opening in viervoud. WRR rapport nr. 80, Amsterdam University Press 2008 (the WRR website, see endnotes, also includes a summary in English: Innovation Renewed).

- Wright, G. H. von, Norm and Action (London: Routledge and Kegan Paul, 1963). 